\title{
Relations in the Size Variation of Plant Organs: a Case Study of Staghorn Sumac Leaves and Longleaf Pine Cone Scales
}

\author{
Xiongwen Chen ${ }^{1}$, Kimberly A. Bowman ${ }^{1} \&$ Zhuo Chen ${ }^{2}$ \\ ${ }^{1}$ Department of Biological \& Environmental Sciences, Alabama A \& M University, Normal, AL 35762, USA \\ ${ }^{2}$ Department of Physics, Emory University, Atlanta, GA 30322, USA \\ Correspondence: Xiongwen Chen, Department of Biological \& Environmental Sciences, Alabama A \& M \\ University, Normal, AL 35762, USA. Tel: 1-256-372-4231. E-mail: xiongwen.chen@aamu.edu
}

Received: December 3, $2021 \quad$ Accepted: January 7, $2021 \quad$ Online Published: January 11, 2022

doi:10.5539/jps.v11n1p1

URL: https://doi.org/10.5539/jps.v11n1p1

\begin{abstract}
Plants automatically control the size variations in organs to achieve efficient exploitation of resources. However, it is unclear whether the scaling relationships of plant organs share a similar character for different individuals under varied micro-conditions (e.g., light and soil water). We conducted a case study of the lengths of staghorn sumac leaves and longleaf pine cone scales to test the relationships. Our results indicated that although there were size variations, there existed power laws of frequency in the lengths of staghorn sumac leaves and longleaf pine cone scales. The exponents differed but were positively correlated with the minimum length of leaves or cone scales. Taylor's Law existed in the lengths of cone scales and some tree leaves, and scale break was observed. This study provides new information on scaling relationships and self-organization in the patterns of tree parts arrangement. Taylor's Law may be used to detect minor changes in the growth regime.
\end{abstract}

Keywords: power laws, scale break, self-organization, tree organs

\section{Introduction}

Size variations in plant organs are essential to function, such as plant seed size and offspring fitness are strongly positively correlated (Mazer, Snow, \& Stanton, 1986), but these variations are automatically adjusted by plants to suit their environment. In order to achieve such diversity to exploit the resource efficiently, plants must adapt their structure to be of various sizes. However, similar relationships among structure and functional variables may be maintained over a wide range of organ sizes (Brown \& West, 2000), described by a fractal dimension or a power function.

Plant leaves are a critical organ to photosynthesis and transpiration, and they play a central role in the growth and survival of a plant. Plant leaves can vary between taxa, individuals in different populations of the same species, and even for some species, within a single plant. Leaf traits represent a necessary trade-off in the many functions over short and evolutionary periods (Nicotra et al., 2011). Leaf traits are currently high in research priority because they are closely linked to many vital aspects of growth, reproduction, and ecosystem functions (Garnier et al., 2001).

There are scaling relationships between leaf traits, such as leaf weight being proportional to leaf area (Milla \& Reich, 2007). These allometric scaling relationships are related to the transfer of heat and mass in the environment (Niklas, 1994) and the thermoregulation processes that constraint hydraulics and mechanics, as well as the avoidance of herbivory and the optimal interception of light (Nicotra et al., 2011). Indices of leaf shape, such as compactness (perimeter ${ }^{2} /$ area) and shape factor $\left(4 \pi \times\right.$ leaf area/perimeter $\left.{ }^{2}\right)$, are used to study leaf shape and its relation to the environment or change with time (Royer, McElwain, \& Adams, 2008; Bacon, Belcher, Haworth, \& McElwain, 2013). The geometric leaf characteristics may be estimated by the general formula (Shi et al., 2018). Some geometric and topological methods indicate that shape variation in the leaves of Ginkgo biloba is dominated by leaf size and furrow depth (Mander, Bauer, Hang, \& Mio, 2020). In compound-leafed species, it is broadly recognized that the geometry of leaflets (e.g., the spatial structure and organization) may determine the compound leaf shape (Scarpella, Barkoulas, \& Tsiantis, 2010; Runions, Tsiantis, \& Prusinkiewicz, 2017).

The arrangement structure of leaf assemblages on a branch may reflect plant self-organization. Leaf traits, such 
as leaf length, are measurable characteristics that represent ecological strategies and functional adaptations to environmental conditions (Pérezharguindeguy et al., 2013). Plant leaves with various shapes enable them to utilize a light resource maximally. Some studies showed that the allometric scaling relationships in size and functional traits of leaves are invariant, such as the scaling exponent approximates $3 / 4$ (West, Brown, \& Enquist, 1999). One study on bamboo branches and internode lengths indicates that both follow power laws, but the scaling exponents are not consistent between species (Chen, 2020). It is unclear whether or how much the scaling relationships of leaves at the same site vary intraspecifically due to varied micro-conditions.

Size variations in reproductive organs are related to seed dispersal, gender expression, and species habitat preferences (Niklas, 1994). These size variations are considered the trade-off between plant physiological and anatomical integration, related to resource allocation. The patterns of size variations may not be similar even to the same plants or plants in a homogeneous environment because plants can have a high degree of physiological autonomy and develop themselves under varied spaces and times (Niklas, 1994). This variation would be expected to follow Taylor's Law, one of the most widely verified empirical relationships in ecology, which has been used to study plant biological systems (Cohen \& Xu, 2015; Chen, Guo, \& Brockway, 2017). Taylor's Law, the logarithm of the variance of a population density (individuals per area or volume), is approximately a linear function of the logarithm of the mean density (Taylor, 1961; Taylor, 2019). Chen \& Chen (2020) studied the fruit size of Chinese Torreya and its size-frequency distribution and found no significant difference in the fruit size (volume, length, width) among different tree individuals. Taylor's Laws were found in the fruit volumes but with varying scaling exponents. Multiple domains were observed in Taylor's Laws for the fruit lengths and widths. It is unclear whether a similar pattern exists in the cone scales of different longleaf pine trees at the same site.

Thus, the goal of this research is to study the scaling relations in tree leaves and pinecone scales. Here we use the leaves of staghorn sumac and cones of longleaf pine as a case study. The detailed objectives include examining (i) whether leaves on a staghorn sumac tree branch follow power laws with a similar exponent among individual trees; and (ii) whether cone scales of longleaf pine follow power laws but with different exponents. This study aims to provide an understanding of patterns in tree parts arrangement.

\section{Material and Methods}

\subsection{Tree Leaves}

Staghorn sumac (Rhus typhina) is a wildly distributed plant species in the southern USA.

It usually grows on the roadside and is tree-like but shrubby. It is easy to reach its leaves and branches. Twigs are stout and not easy to break down. Leaves are compound, alternate, and 20 to 40 centimeters long. There are many leaves (e.g., > 20 leaves) on one branch. These traits make it a good choice for this study. One branch in each tree was selected randomly. The length of every leaf was measured and recorded based on its sequence on the branch of each tree. Five trees were selected based on the accessibility along the Bradford Creek greenway at Madison City in Alabama $\left(34.7215^{\circ} \mathrm{N}, 86.7832^{\circ} \mathrm{W}\right)$.

\subsection{Longleaf Pine Cones}

Longleaf pine (Pinus palustris) is native to the southeastern region in the United States. This tree species is mainly distributed along the coastal plain from East Texas to southern Virginia. The regeneration of longleaf pine forests primarily relies on its seeds or cone production (Chen, Brockway, and Guo, 2018). The longleaf pine cones are the largest in the southern pines and range from 5 to 12 inches in length. Although the seeds are hard to collect, their scales are easy to measure due to their large sizes. Five already dropped cones from the different spots at the same forest stand (approximately $20 \mathrm{~m}$ tall and 85 years old) at Braden Lake State Forest in North Carolina $\left(34.7068^{\circ} \mathrm{N}, 78.5941^{\circ} \mathrm{W}\right)$ were used for this study. The length of each cone scale was measured after it was detached from the cone.

\subsection{Methods}

\subsubsection{Power Law of Frequency}

The lengths of leaves (or cone scales) were counted based on an increment of $1 \mathrm{~cm}$ (or $0.5 \mathrm{~cm}$ for cone scale). For example, a leaf with a length of $6.4 \mathrm{~cm}$ was in the length category of $\leq 7.0 \mathrm{~cm}$. The number of leaves within each category was counted. After that, the cumulative percentages of the leaf lengths below different thresholds were calculated for all leaves on a branch (White, Enquist, \& Green, 2008) as:

Percentage $=100 \times$ the number of leaves (or scales) in a category/the total number of leaves (or scales) on one branch (or one cone).

A figure with the logarithm of the leaf (or cone scale) length below the value of each length threshold (such as $\leq$ 
$7.0 \mathrm{~cm}$ ) and the logarithm of the cumulative percentage $(\mathrm{P})$ was produced. The power law of frequency was estimated through the best linear fitting.

\subsubsection{Taylor's Law}

In this study, Taylor's Law (Taylor, 1961; Taylor, 2019) is expressed in the following way:

Variance $=\mathrm{a} \times$ Mean $^{\mathrm{r}}$

with Variance as the variance of leaf (or cone scale) length, $a$ as the coefficient, and Mean as the average leaf (or cone scale) length.

After logarithm, $\log ($ Variance $)=\log ($ a) $+r \times \log$ (Mean).

With leaf (cone scale) number of $n$ from tip to base, the scaling exponent $(r)$ between the variance and average of $n$ leaf (or cone scale) lengths was estimated for each plant organ (branch or pinecone).

\subsection{Statistical Analysis}

ANOVA and T-Test of SAS software (Cary, NC, USA) were used to compare variations in the lengths and scaling exponents between individual tree branches (or pinecones), respectively. The commonly used least mean squares technique was used in regression analysis for linear fitting.

To be consistent with the literature on the estimation of allometric relationships, a reduced major axis (RMA) of regression analysis Model Type II was used to determine scaling exponents (e.g., Niklas, 1994). Differences were considered significant when $\mathrm{p}<0.05$ or very significant as $\mathrm{p}<0.01$.

\section{Results}

The length of sumac leaves ranged from 3.0 to $11.9 \mathrm{~cm}$ (Table 1) and also the number of leaves on branches varied. The average leaf lengths were from $7.6 \mathrm{~cm}$ to $9.4 \mathrm{~cm}$ in different trees, but there was no significant difference among trees $(\mathrm{p}>0.05)$. However, the lengths of longleaf pine cone scales were longer in cone I and IV than cone III $(\mathrm{p}<0.05)$.

Table 1. The measurement information of tree leaves of five staghorn sumac and cone scales of longleaf pine

\begin{tabular}{lllllll}
\hline & & I & II & III & IV & V \\
\hline Leaves & Total number & 73 & 63 & 42 & 69 & 28 \\
& Average length $(\mathrm{cm})$ & $8.6(1.6)$ & $9.1(1.3)$ & $8.4(1.5)$ & $8.6(1.8)$ & $8.2(2.0)$ \\
& Length range $(\mathrm{cm})$ & $3.0 \sim 11.4$ & $4.2 \sim 11.9$ & $4.5 \sim 10.6$ & $3.4 \sim 11.6$ & $3.0 \sim 10.6$ \\
Cone scales & Total number & 112 & 96 & 81 & 86 & 81 \\
& Average length $(\mathrm{cm})$ & $4.6^{\mathrm{a}}(1.0)$ & $3.8^{\mathrm{ab}}(0.6)$ & $3.3^{\mathrm{b}}(0.4)$ & $4.3^{\mathrm{a}}(0.6)$ & $3.5^{\mathrm{ab}}(0.4)$ \\
& Length range $(\mathrm{cm})$ & $1.4 \sim 5.9$ & $2.5 \sim 4.8$ & $2.2 \sim 4.1$ & $2.8 \sim 5.9$ & $2.5 \sim 4.4$ \\
\hline
\end{tabular}

*: In the average length, different letters (a and $\mathrm{b}$ ) after the values indicate the statistical difference between the average lengths $(\mathrm{p}<0.05)$.

Power law of frequency was found in the leaves on the branches of staghorn sumac with statistically significant ( $\mathrm{p}<0.01$ ) (Fig. 1) but with different exponents. These exponents varied from 2.8 to 5.9 and were positively correlated with the minimum leaf length of each branch (Fig. 2), and the scaling exponent (0.7712) among different trees had no significant difference with $3 / 4$. The lengths of staghorn sumac leaves varied on each branch and the self-organization regime (such as the variation of lengths) might be quite different (e.g., diverse scaling exponents). However, this self-organization regime could be related to the minimum leaf length in different trees. 

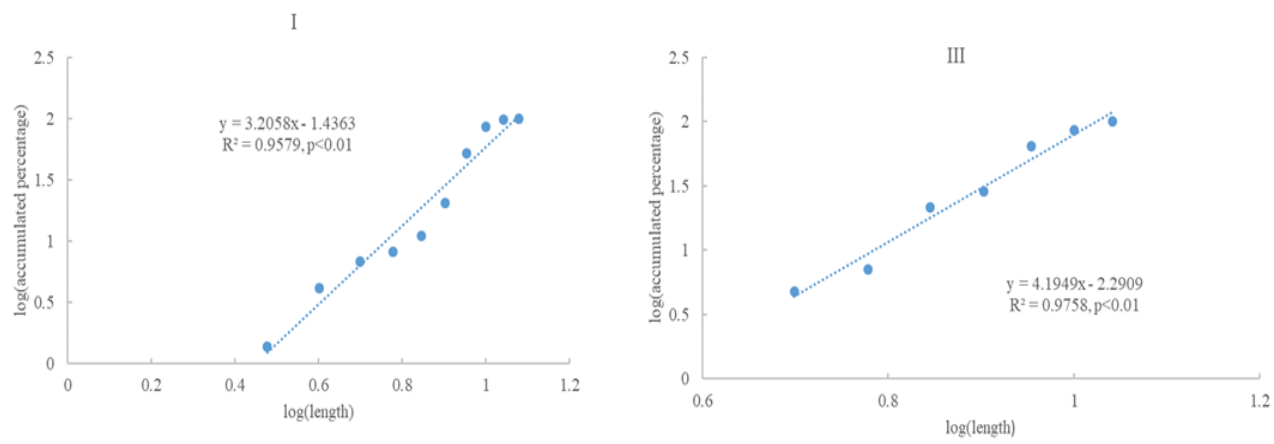

II

IV
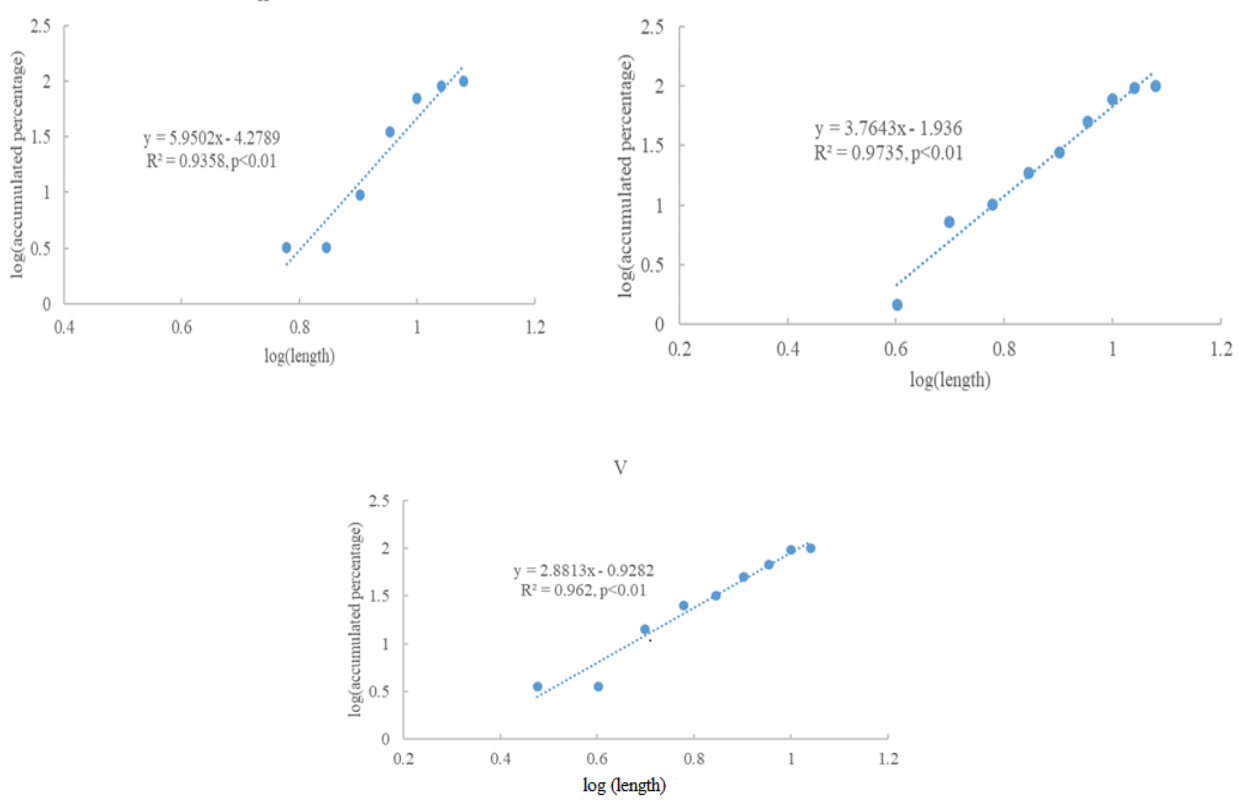

Figure 1. Power law of frequency in leaf lengths of staghorn sumac

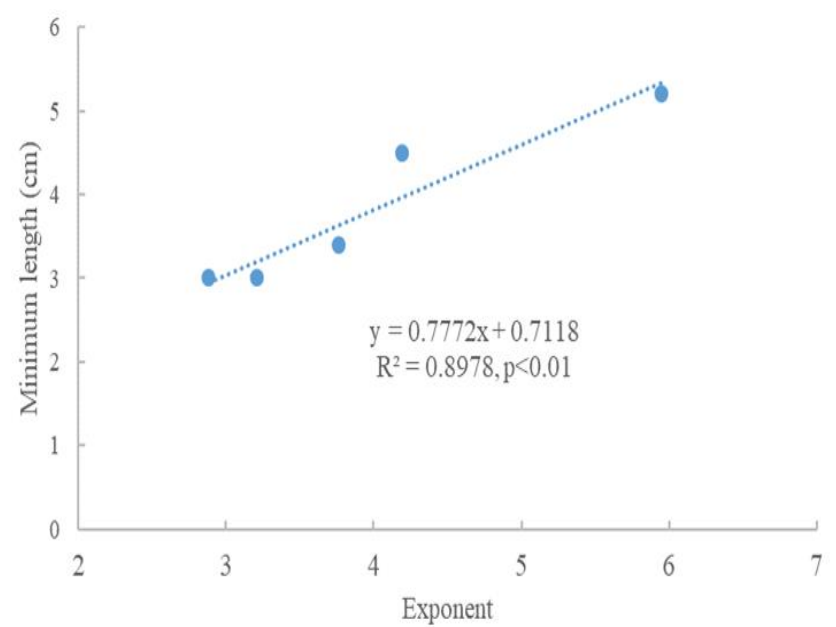

Figure 2. Correlation between scaling exponents and minimum of leaf length in staghorn sumac

Similar to the leaves, the lengths of cone scales also followed the power law of frequency very significantly but with different exponents $(3.2 \sim 5.0)$ ( p < 0.01) (Fig. 3), and these exponents were positively correlated with the minimum cone scale length on each pinecone ( $p<0.01)$ (Fig. 4). The scaling exponent (0.7621) among different cones had no significant difference with $3 / 4$. The self-organization regime (such as the variation of scale lengths) 
of each cone might be quite different (e.g., diverse scaling exponents), but this self-organization regime might be related to the minimum scale length in different cones.
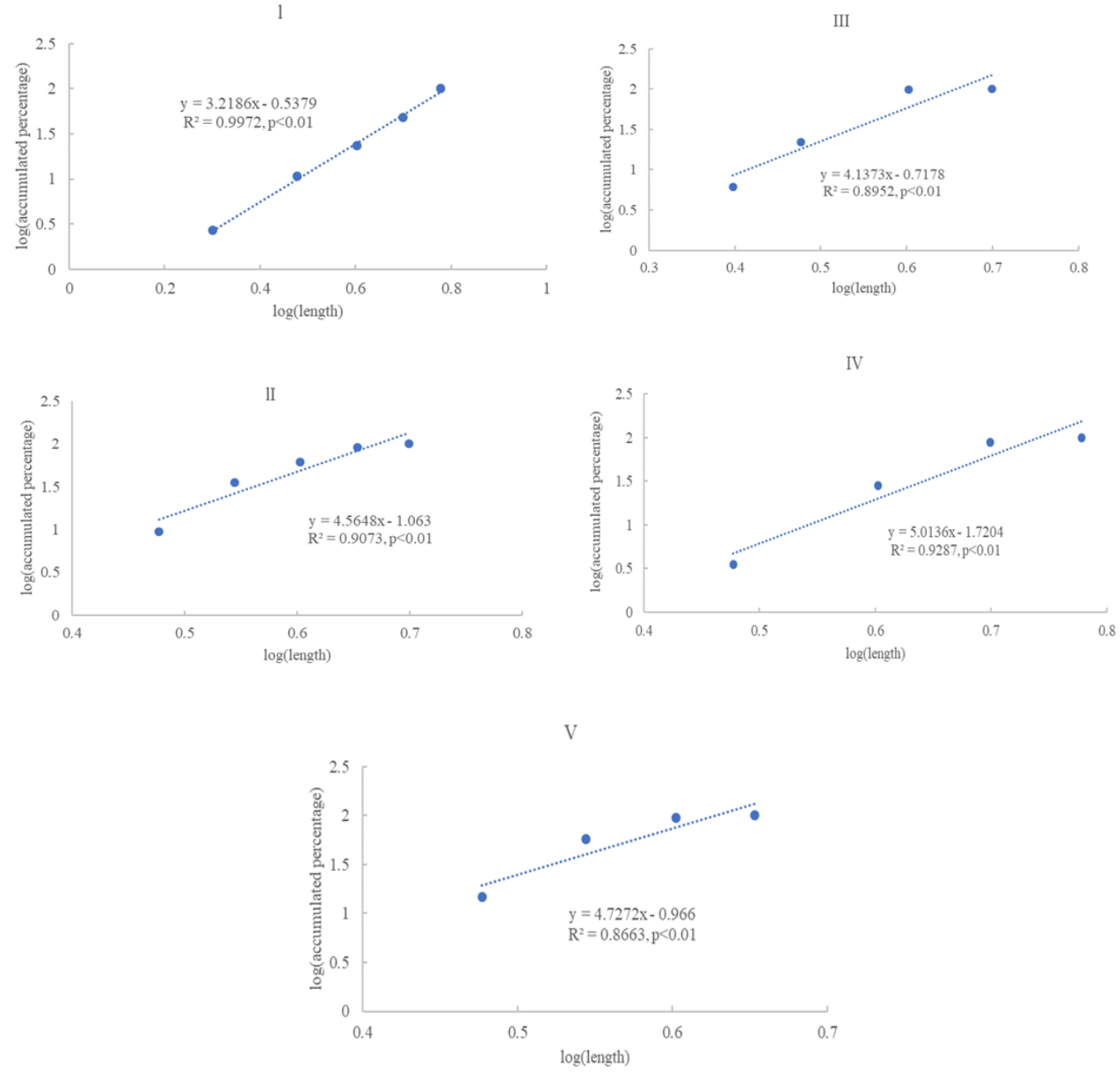

Figure 3. Power law of frequency in cone scale lengths of longleaf pine

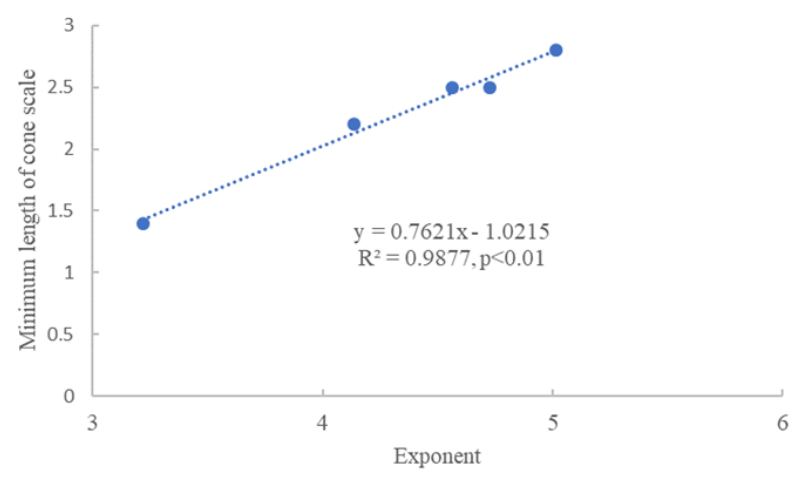

Figure 4. Correlation between scaling exponents and minimum lengths of cone scale in longleaf pine

Taylor's Law existed in the leaf lengths of two trees (tree III and IV) $(\mathrm{p}<0.05)$ (Fig. 5a). For others, it was not statistically significant (Fig. 5b) ( $\mathrm{p}>0.05$ ). Taylor's Law existed in the length of cone scales for each cone significantly $(\mathrm{p}<0.05)$ (Fig. 6), but the scale break was apparent. Some scales might have different regimes in the self-organization of lengths. 
III

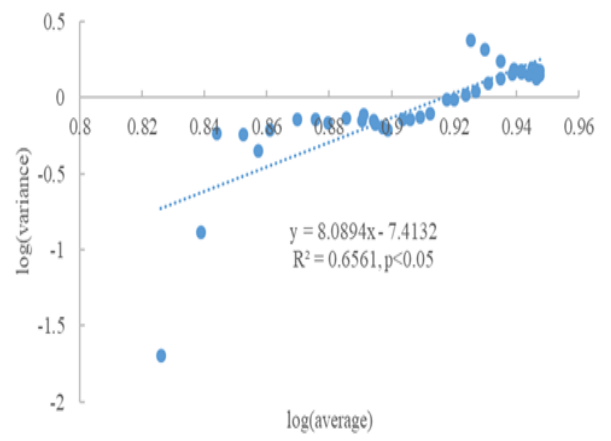

IV

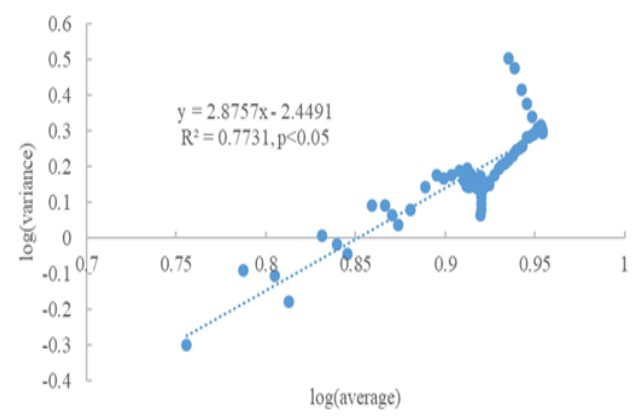

Fig. 5a

I

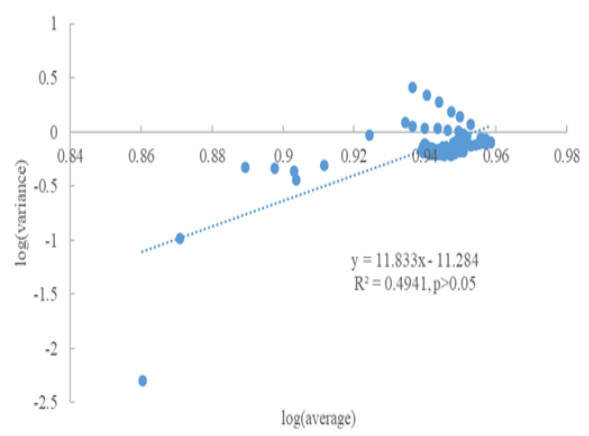

II

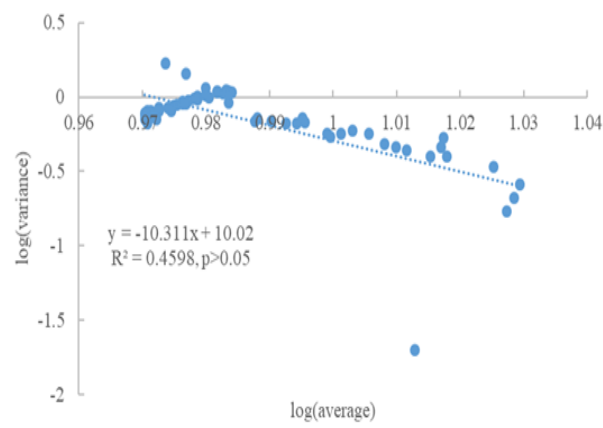

V

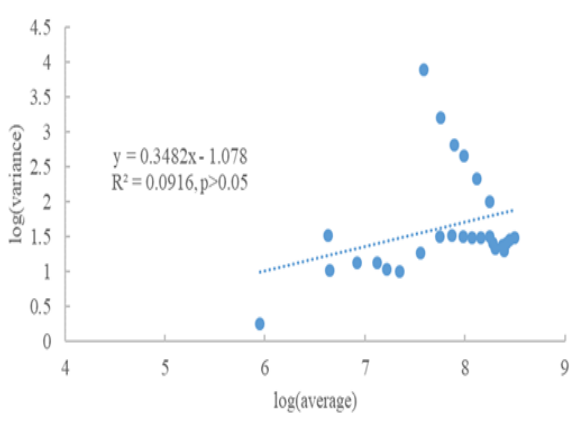

Fig. $5 b$

Figure 5. Taylor's Law was significant in leaf lengths of staghorn sumac (tree III and IV) (a), but not significant in others (b) 


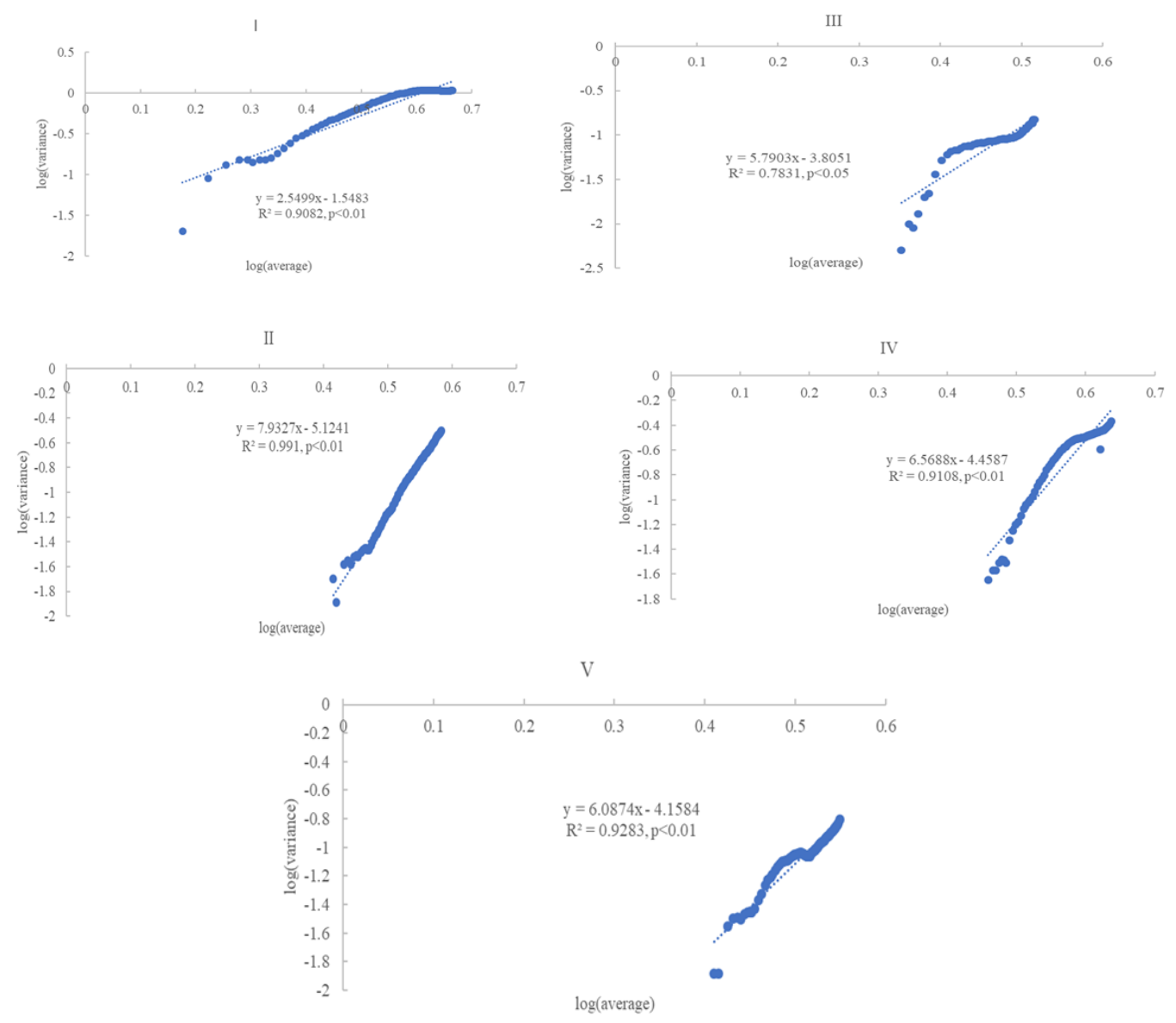

Figure 6. Taylor's Law in cone scale lengths of longleaf pine

\section{Discussion}

No matter the length variations, both leaves and cone scales followed power laws of frequency, but with different exponents (Fig. 1, Fig. 3), which are correlated with the minimum length of leaves and cone scales, respectively (Fig. 2, Fig. 4). Power laws of frequency are considered the general law, which can be widely applied in different conditions to indicate the scaling relations (White et al., 2008). This result is consistent with the frequency of fruit size (Chen \& Chen, 2020). It is considered that the difference in the frequency distribution of plant organs (e.g., fruits, leaves, and cone scales) may be caused by nutrient levels in trees and microenvironmental conditions, such as sunlight. Light time and quantity can affect fruit growth through photosynthesis. Due to the canopy structure, light transmission and distribution at the tree canopy can be significantly heterogeneous among trees. This mechanism of self-organization is evident on fruit trees, such as big fruits are often found at the canopy outside with good light condition while the small ones are located in the low inner part (Warrington, Stanley, Tustin, Hirst, \& Cashmore, 1996). The difference in leaf shape for some plants might be an adaptive response to different habitats (Shi et al., 2018). The plant hormone auxin can control the lateral development of branches (Roychoudhry, Del Bianco, Kieffer, \& Kepinski, 2013). Thus, the exponents of power laws show the strategy of energy allocation in plants. The results here indicate various rather than a fixed value in the scaling exponents for each branch, which is consistent with previous studies (e.g., Chen, 2018). Since the lengths of cone scales may be related to the seed sizes of longleaf pine, the seed size and quantity could be linked to the restoration of longleaf pine forests. But the scaling exponents among different individual trees or cones were not significantly different from 3/4 (Fig, 2, Fig. 4). Since only five trees or cones were included in this study, more samples are needed to test whether the scaling exponent across different trees is still within the value of $3 / 4$. Further long-term studies should be conducted on the relation between cone scales, seed size, and seedling regeneration.

Taylor's Laws provide detailed information on size variation in leaves and cone scales. They can indicate the scale break (or shift) in the size variations. The leaf lengths of three trees (\#I, II, and V) did not follow Taylor's 
Laws (Fig. 5b). This result may be partially related to the time of this observation (July), since staghorn sumac maybe not fully mature during that time. A previous study on Crape myrtle indicated that temporal dynamics in scaling exponents could exist (Chen, 2017). Despite Taylor's Laws in the lengths of cone scales, some scale break or shift could be seen obviously (Fig. 6), especially at the small sizes. When trees are young, they have high bifurcation in geometry (Borchert \& Slade, 1983). Plant organs are self-organized products. The scale break and multiple domains in average length and variance relations may indicate different driving forces or regime shifting in organ growth (e.g., sunlight and soil water). Scaling exponents may reflect the difference in living conditions, including all interactions among all elements of the living system (Arruda-Neto et al., 2012). Our methods may be applied to study the pattern variation of plant organs in fossil and modern material alike.

\section{Conclusion}

As a case study of plant organs, for the lengths of leaves in staghorn sumac and longleaf pine cone scales, there existed power laws of frequency, but the exponents differed. Taylor's Law existed in the lengths of cone scales and some leaves. The approach of Taylor's Law could be used to identify the scale break and domains. The power laws are related to the energy allocation in plant organs. The methods may be used to study the evolution of plant organs. Further research should be conducted to identify the underlying mechanisms through long-term and well-controlled experiments.

\section{Acknowledgments}

This research was supported by the USDA National Institute of Food and Agriculture McIntire Stennis project (1008643) and the Capacity Building Program (2021-38821-34596).

\section{References}

Arruda-Neto, J. D. T., Bittencourt-Oliveira, M. C., Castro, A. C., Rodrigues, T. E., Harari, J., Mesa, J., \& Genofre, G. C. (2012). Global warming and the power-laws of ecology. Atmospheric and Climate Sciences, 2, 8-13. https://doi.org/10.4236/acs.2012.21002

Bacon, K. L., Belcher, C. M., Haworth, M., \& McElwain, J. C. (2013). Increased Atmospheric $\mathrm{SO}_{2}$ Detected from Changes in Leaf Physiognomy across the Triassic-Jurassic Boundary Interval of East Greenland. Plos ONE, 8, e60614. https://doi.org/10.1371/journal.pone.0060614

Borchert, R., \& Slade, N. A. (1983). Bifurcation ratios and the adaptive geometry of trees. Botanical Gazette, 142, 394-401. https://doi.org/10.1086/337238

Brown, J. H., \& West, G. B. (2000). Scaling in Biology. New York, NY: Oxford University Press.

Chen, X. (2017). Allometric dynamics in branch growth of crape myrtle. Journal of Plant Studies, 6, 28-37. https://doi.org/10.5539/jps.v6n2p28

Chen, X. (2018). Diverse scaling relationships of tree height and diameter in five tree species. Plant Ecology and Diversity, 11, 147-155. https://doi.org/10.1080/17550874.2018.1445128

Chen, X. (2020). Variations in patterns of internode and branch lengths for several bamboo species. Plant Biosystems. https://doi.org/10.1080/11263504.2020.1829729

Chen, X., Brockway, D. G., \& Guo, Q. (2018). Characterizing the dynamics of cone production for longleaf pine forests in the southeastern United States. Forest Ecology \& Management, 429, 1-6. https://doi.org/10.1016/j.foreco.2018.06.014

Chen, X., \& Chen, X. (2020). Variation of fruit size and its frequency distribution in Chinese Torreya. International Journal of Fruit Science, 20, s1445-s1457. https://doi.org/10.1080/15538362.2020.1802395

Chen, X., Guo, Q., \& Brockway, D. G. (2017). Power laws in cone production of longleaf pine across its native range in the United States. Sustainable Agricultural Research, 4, 64-73. https://doi.org/10.5539/sar.v6n4p64

Cohen, J. E., \& Xu, M. (2015). Random sampling of skewed distributions implies Taylor's power law of fluctuation scaling. Proceeding of National Academy of Science USA, 112, 7749-7754. https://doi.org/10.1073/pnas.1503824112

Garnier, E., Laurent, G., Bellmann, A., Debain, S., Berthelier, P., Ducout, B., Roumet, C., \& Navas, M.-L. (2001). Consistency of species ranking based on functional leaf traits. New Phytologist, 152, 69-83. https://doi.org/10.1046/j.0028-646x.2001.00239.x

Mander, L., Bauer, M., Hang, H., \& Mio, W. (2020). Geometric and topological approaches to shape variation in Ginkgo leaves. BioRxiv. https://doi.org/10.1101/2020.10.23.352476 
Mazer, S. J., Snow, A. A., \& Stanton, M. L. (1986). Fertilization dynamics and parental effects upon fruit development in Raphanus raphanistrum: Consequence for seed size variation. American Journal of Botany, 73, 500-511. https://doi.org/10.1002/j.1537-2197.1986.tb12068.x

Milla, R., \& Reich, P. B. (2007). The scaling of leaf area and mass: The cost of light interception increases with leaf size. Proceeding of the Royal Society of Biological Science, 274, 2109-2114. https://doi.org/10.1098/rspb.2007.0417

Nicotra, A. B., Leigh, A., Boyce, C. K., Jones, C. S., Niklas, K. J., Royer, D. L., \& Tsukaya, H. (2011). The evolution and functional significance of leaf shape in the angiosperms. Functional Plant Biology, 38, 535-552. https://doi.org/10.1071/FP11057

Niklas, K. J. (1994). Plant Allometry: The scaling from Form and Process. Chicago, IL: The University of Chicago Press.

Pérezharguindeguy, N., Díaz, S., Garnier, E., Lavorel, S., Poorte, H., Jaureguiberry, P., ... Cornelissen, J. H. C. (2013). New handbook for standardised measurement of plant functional traits worldwide. Australian Journal of Botany, 61, 167-234. https://doi.org/10.1071/BT12225_CO

Runions, A., Tsiantis, M., \& Prusinkiewicz, P. (2017). A common developmental program can produce diverse leaf shapes. New Phytologist, 216, 401-418. https://doi.org/10.1111/nph.14449

Roychoudhry, S., Del Bianco, M., Kieffer, M., \& Kepinski, S. (2013). Auxin controls gravitropic setpoint angle in higher plant lateral branches. Current Biology, 23, 1497-1504. https://doi.org/10.1016/j.cub.2013.06.034

Royer, D., McElwain, J., \& Adams, J. (2008). Sensitivity of leaf size and shape to climate within Acer rubrum and Quercus kelloggii. New Phytologist, 179, 808-817. https://doi.org/10.1111/j.1469-8137.2008.02496.x

Scarpella, E., Barkoulas, M., \& Tsiantis, M. (2010). Control of leaf and vein development by auxin. Cold Spring Harbor Perspectives in Biology, 2, a001511. https://doi.org/10.1101/cshperspect.a001511

Shi, P., Ratkowsky, D. A., Li, Y., Zhang, L., Lin, S., \& Gielis, J. (2018). A general leaf area geometric formula exists for plants-evidence from the simplified Gielis equation. Forests, 9, 714. https://doi.org/10.3390/f9110714

Taylor, L. R. (1961). Aggregation, variance and the mean. Nature, 189, 732-735. https://doi.org/10.1038/189732a0

Taylor, R. A. J. (2019). Taylor's Power Law: order and pattern in nature. Academic Press.

Warrington, I. J., Stanley, C. J., Tustin, D. S., Hirst, P. M., \& Cashmore, W. M. (1996). Light transmission, yield distribution, and fruit quality in six tree canopy forms of 'Granny Smith' apple. Journal of Tree Fruit Production, 1, 27-54. https://doi.org/10.1300/J072v01n01_03

West, G. B., Brown, J. H., \& Enquist, B. J. (1999). A general model for the structure and allometry of plant vascular systems. Nature, 400, 664-667. https://doi.org/10.1038/23251

White, E. P., Enquist, B. J., \& Green, J. L. (2008). On estimating the exponent of power-law frequency. Ecology, 89, 905-912. https://doi.org/10.1890/07-1288.1

\section{Copyrights}

Copyright for this article is retained by the author(s), with first publication rights granted to the journal.

This is an open-access article distributed under the terms and conditions of the Creative Commons Attribution license (http://creativecommons.org/licenses/by/4.0/). 